\title{
Cartas privadas y actitudes lingüísticas en España y América durante los siglos XVIII y XIX. Algunos problemas en el modo de acceso al objeto de estudio
}

\author{
Manuel Rivas Zancarrón (Universidad de Cádiz, España)
}

\begin{abstract}
Together with an oral manifestation put into practice by tradition since birth, necessity drove ordinary people to develop the ability to speak with an absence of the self, the you and the communicative situation. Initially, it was the emigration to America, promoted by the miseries of a decadent homeland, which contributed to the development of a textual genre of urgency, without literary retensions, which in later years became a sign of good education on the part of those using it. With this work, we review the methodological pitfalls that are hidden when accessing this type of object. We analyse the difficulties that might be found by researchers when facing these documents from a philological point of view and from the sociolinguistic view of the attitudes of the speakers-both implicit and explicit. The concept of "discursive tradition" will act as a methodological moderator and will allow the construction of a bridge between diachronic Sociolinguistics and Language History in the recovery of oral remains from the speech of the 18th and 19th centuries in Spain and America.
\end{abstract}

Keywords: historical sociolinguistics, linguistic attitudes, discursive traditions, 18th and 19th centuries, language history

\section{Introducción}

En el mes de julio de 2017, irrumpió en las redes sociales una polémica lingüística de la mano del académico y conocido escritor español Arturo Pérez Reverte. A través de los escasos caracteres de un tweet, anunciaba el autor del Capitán Alatriste que, en breve, esto es, antes de que acabara el año en curso, la Real Academia daría por bueno — en virtud del uso y la costumbre - el empleo de la forma iros por la hasta ahora autorizada idos. El eco de este corto mensaje caló en la prensa de esos días, hasta el punto de que muchos fueron los periódicos los que, aprovechando la primicia de un infiltrado legítimo de la Corporación académica, convirtieron un comentario aislado en noticia. Este hecho, que parece no tener la menor trascendencia, abrió un pequeño debate entre los ciudadanos de a pie - ya a través de tweeter, ya desde los foros de la prensa escrita-, en donde el busilis de la cuestión se situaba curiosamente en torno al mismo concepto que generó disputas sobre la lengua en el siglo XVIII español: el purismo. Mientras unos bendecían la resolución académica de aceptar lo que los nuevos tiempos piden, otros criticaban el doblegamiento de la Institución ante la apertura de barrera a un intruso que podría ayudar a contaminar la elegancia de la lengua. Una discusión así en los tiempos que corren no es baladí y esconde dos moralejas que aleccionarán los resultados de este trabajo: 1) el común de los hablantes $-\mathrm{y}$ dependiendo del nivel de 
instrucción - suele acatar con respeto, y siempre que le llegue a sus oídos la nueva ley normativa, lo que establece una corporación de sabios autorizados, y 2) si no hay aceptación a la nueva regla dictaminada por el uso, el hablante se cierra a lo antiguo, por considerar que lo nuevo afea el hablar y el escribir. Ya digo que la verdad de estas moralejas se hace depender en estos tiempos de la variable sociolingüística «nivel de estudios», pues la de «sexo» parece estar desactivada en la actualidad, frente a lo que acontecía en los siglos XVIII y XIX, en donde la mujer solía ser más conservadora ante las normas dictadas por escrito. Efectivamente, como se da a entender en múltiples comentarios y valoraciones vertidos en diferentes medios escritos de los siglos XVIII y XIX, son los intelectuales — especialmente los gramáticos - los que más se han enfrentado al «limpia, fija y da esplendor», pero, paradójicamente, los juicios beligerantes de estos individuos especializados en el arte de la gramática no calaban en los usuarios del idioma. Este hecho vendría a significar que una parte de la influencia real sobre el cambio linguíístico se consumaría gracias a la intervención de la Real Academia de la lengua —ya por reacción a favor, ya por reacción en contra-, mientras que los escritos críticos de los gramáticos llegaban como pavesas a los ciudadanos. ¿Y qué repercusión ha tenido o puede tener en el hablar de la calle una discusión como la originada en las redes sociales? Pues, para empezar, una parte de los hablantes no solo se ha percatado de que iros se ha vuelto admisible a los ojos de la norma prescriptiva, sino que también se ha enterado indirectamente de lo que exigía el uso correcto y que nunca puso en boca, esto es, la forma idos. De resultas, puede ocurrir - como demuestran los giros de orientación en los cambios lingüísticos - que los hablantes desconocedores de la forma correcta la prefieran a partir de este momento, en lugar de aquella que utilizaban y que ahora se acepta, con lo que el advenimiento de una norma nueva puede ayudar a reavivar una antigua y a convertir esta en modelo de uso habitual. Todo depende de a qué sectores sociales alcance y el grado de exposición pública de los datos.

Pues bien, con este ejemplo hemos querido ilustrar la importancia de acceder a un objeto de estudio concreto tras la consideración de múltiples variables, ya que si estas no han sido tratadas adecuadamente, difícilmente podríamos llegar a corolarios coherentes. El escaso espacio del que disponemos para llevar a cabo este trabajo nos obliga a centrarnos exclusivamente en los aspectos metodológicos que habrán de ser considerados a la hora de investigar las actitudes lingüísticas emanadas de los textos epistolares de España y América en los siglos XVIII y XIX. A pesar de que habrá que dejar para otros estudios la extensa justificación documental de posibles conclusiones que aquí se extraigan, sí trazaremos los principales escollos con los que se encontrará el investigador a la hora de enfrentarse con estos documentos y decidir qué importancia tienen en el trasiego de las formas lingüísticas.

\section{Sobre método de acceso y entorno sociocultural}

Llevar a cabo una incursión en los escritos epistolares de los siglos XVIII y XIX presupone estar al tanto del contexto sociopolítico que condicionó su producción y, además, dar cuenta del motor explicativo que mejor se adapte a la delimitación del objeto de estudio. No cabe duda de que un acercamiento filológico a las cartas privadas escritas durante los siglos en litigio contempla la intervención, cuando menos, de dos disciplinas históricas: la sociolingüística diacrónica y la historia de la lengua. La primera deberá activar las diferentes variables que han podido ser determinantes en la producción de esos textos, cuyos resultados ayudarán a la segunda a replantear, quizá, algunas de las orientaciones propuestas para la explicación del cambio lingüístico. Dentro de la sociolingüística, el detenimiento en las actitudes o valoraciones - explícitas o implícitas - que se traslucen en este tipo concreto de 
hablantes configurará un universo de preguntas, cuyas respuestas justificarán el número de constantes teóricas. Por sí solos, no obstante, estos principios metodológicos no son suficientes para extraer conclusiones sobre la constitución lingüística de estos textos, pues la participación de lo externo — de lo sociopolítico y económico, en este caso- necesita de puentes para garantizar la explicación adecuada de procesos internos. Aquí es donde las dos disciplinas anteriores quedarían interconectadas. Y para contribuir a forjar esta unión, es indispensable sintonizar el objetivo del análisis filológico: detenernos en cuánta oralidad puede verse reflejada en este producto linguístico. Sin duda, las actitudes de los que escribían estas cartas contribuirían a descubrir cuál podría ser el uso linguiístico real, pero las conclusiones desprendidas de aquí deben pasar por un nuevo tamiz conceptual que determine el grado de oralidad o escrituralidad que estas manifestaciones delatan. Creemos que este filtro vendría regulado por el concepto de «tradiciones discursivas», que, además de determinar si lo que se dice es producto del hablar o del escribir — tras la ubicación del texto en una tradición dinámica-, podrá adelantar también la importancia que tienen estas manifestaciones externas en el cambio lingüístico. Téngase en cuenta que, como veremos, los agentes de estas producciones no tenían por qué coincidir con los sujetos que las firmaban; es más, lo que nos enseña la disciplina histórica es que el entorno social — caracterizado, para el caso que ahora nos atañe, por un alto grado de analfabetismo - hace pensar que el escribiente no era el hablante. Por todo ello, parece precavido no lanzar corolarios, argumentados desde una simple ojeada al texto, pues ni siquiera la grafía, en estas circunstancias, es garante de los posibles reflejos diatópicos, diastráticos y diafásicos. Además, como cualquier tradición discursiva, la epistolar ha debido hacerse con el tiempo y de acuerdo a unas fórmulas, las cuales habría que indagar para no estar confundiendo rasgos orales con discurso repetido escrito. De hecho, cuanto más evoluciona una tradición, más se aleja del lenguaje de la cercanía y más se acerca al de la distancia.

Con estos planteamientos, será, pues, de un lado, el concepto de actitudes lingüísticas, o sea, las valoraciones explícitas o implícitas que los hablantes tenían de su hablar o escribir, el que debería conducir el análisis de estas cartas; de otro, convendría aplicar el filtro de la orientación teórica conocida como «tradiciones discursivas», con objeto de separar del análisis todo aquello que contribuya a su falseamiento ${ }^{1}$.

\footnotetext{
${ }^{1}$ En el ámbito del español, fueron Rona (1974) y luego López Morales (1989) quienes pronosticaron las bondades de explotar el concepto de actitudes lingüísticas, pues se perfilaría como el más adecuado para una investigación que conectase lo social con la lengua, en el sentido de influir sobre fenómenos internos concretos (cf. también Carranza 1982), además de contribuir a ser un elemento complementario para un mejor conocimiento de la competencia comunicativa. Es cierto que el concepto de «actitud» ha estado sujeto a múltiples interpretaciones, sobre todo en el terreno de la psicología, pero en el ámbito sociolingüístico se acepta como aquella opinión crítica y valorativa que tienen los hablantes sobre aspectos concretos de la lengua, sobre dialectos o sobre diasistemas (cf. R. Appel y P. Muysken 1987). Cualquier valoración que se haga sobre un sistema de comunicación (si este es feo o bonito, si es puro o bárbaro, si se defiende un dialecto o una norma de prestigio [cf. Fasold 1984])...) puede valer aquí como instrumento de análisis. Desde un punto de vista metodológico, encontramos una defensa del concepto desde múltiples perspectivas: desde las reacciones de los hablantes ante el uso lingüístico (cf. Blanco de Margo 1991) —quizá la visión más apropiada para un enfrentamiento diacrónico—, hasta los enfoques más mentalistas (cf. Agheyisi y Fishman 1970), que, por su carácter predictivo, son los más atrayente para un estudio sincrónico. Desde un punto de vista histórico se multiplican los análisis basados en este tipo de concepciones (cf. Darío Rojas 2015 o Blas Arroyo 1999).

En cuanto al concepto de «tradiciones discursivas», viene siendo fruto en estos últimos años de continuas investigaciones en el seno de la filología alemana, donde nació. Efectivamente, en los años 60, apareció un regusto por trabajos que ponían en conexión la lengua con la realidad, a diferencia del encorsetamiento inmanentista que caracterizó la corriente estructural desde su fundación con Saussure y su desarrollo posterior a través de las escuelas de Praga y Copenhague. Esta nueva forma de ver las cosas estimuló a Eugenio Coseriu a un cambio de
} 
$\mathrm{Y}$ antes de entrar a describir los detalles que relatan los posibles modos de acceso filológicos al objeto de estudio aquí planteado, conviene pincelar brevemente los acontecimientos socioculturales que pudieron hacer mella en el destino de la lengua española durante los siglos XVIII y XIX, pues los métodos antes reseñados no podrán eludirlos a la hora de aplicar sus filtros.

Recordemos, pues, que el primer siglo puesto en foco, el XVIII, quería, de un lado, abrirse al mundo por su anhelo de conocimiento, pero, de otro, cerraba sus posibilidades de apertura por una defensa de la la idiosincrasia cultural de cada pueblo, que afectaba igualmente a la lengua. En 1713, se funda la Real Academia Española, que tenía la atrevida y difícil misión de fijar y limpiar las impurezas del castellano, aunque su primera gran obra, el Diccionario de Autoridades (1726-1739), tuviera tan solo un carácter erudito, sin más pretensiones - y nada menos - que las de recoger entre sus pastas el acervo de una lengua que llevaba viviendo más de cinco siglos. La admisión de uno u otro vocablo se hacía depender del fetiche de lo escrito, donde el uso maestro por parte de un escritor u obra destacada era justificación suficiente como para dar protagonismo al vocablo dentro del diccionario. Es cierto que Adrián Konnink, el prologuista de tan afanoso trabajo, ya advertía en las primeras páginas sobre la necesidad de simplificar y reformar el sistema gráfico del castellano, pues abarcar tantos siglos de vida aprieta mucho sobre el corsé evolutivo de la lengua, en razón de que los años desgastaban poco a poco la osamenta fonológica y convertían el escribir en un cuerpo inarticulado por la evolución de las articulaciones fonéticas. La desaparición de rasgos distintivos contribuía a la confusión gráfica, que exigía ser resuelta por una simplificación, nacida de una idea que combinaba el principio quintiliano del «escribo como pronuncio» con la fuerza del uso y la costumbre. Las instrucciones ofrecidas en el prólogo del Diccionario, antesala de la reforma ortográfica de 1741, calaron sobre todo en las letras de molde, pues ellas, más que ningún otro agente, tenían necesidad práctica de eliminar un sobrante que se repetía y alternaba sin justificación en el hablar. Lástima que las plantas lexicográficas de esta obra obviaran los detalles de su prólogo, ya que sus entradas se vieron duplicadas y triplicadas no en relación a las diferencias de contenido, sino a la distinta manifestación gráfica que se rescataban de las fuentes tomadas a consulta. Así, podía ocurrir que se introdujeran dos o tres formas diferentes referidas a una misma autoridad solo por el hecho de considerar varias ediciones o manuscritos de un mismo autor, o, aun siendo una misma versión, rescatar las distintas manifestaciones que, en virtud del mare magnum gráfico, se reflejaban a lo largo del texto impreso (cf. Rivas Zancarrón 2017).

Con estos condicionantes, en donde se entrecruzaban las ideas del cuidado hacia la lengua de un pueblo y la necesidad de atender nuevos saberes, las actitudes hacia cómo se debería hablar o escribir vacilaban entre el freno purista y el desenfreno del conocimiento. Este último acabó arrastrando de lo extraño con más ímpetu y consiguió justificarse en los primeros momentos del siglo desde la lengua madre, el latín. Conforme avanzaba la centuria, no hubo más remedio que admitir intrusos desde el francés o el inglés, aunque con tiras y aflojas

perspectiva, en donde el texto, el habla real, también debería contar en el análisis. Su enfoque sobre los «tres niveles del lenguaje» (cf. Coseriu 1977), que procedía de la axiomática bühleriana, alentaba al estudio del Sprechakt («acto verbal»), hasta el punto de que sus discípulos comenzaron a ver nuevas posibilidades metodológicas, sobre todo en el análisis de procesos históricos (cf. Schlieben-Lange 1983). La alusión a una posible nueva disciplina, la pragmática histórica, fue el inicio de las «tradiciones discursivas» como concepto (cf. Kabatek 2000, 2008; Koch/Oesterreicher 2011...), en donde se admitía que «los textos tienen historia y [...] esa historia tiene relevancia a la hora de hablar o de escribir, por lo que hay que tener en cuenta esas "tradiciones discursivas" en la descripción lingüística, inclusive la descripción gramatical"» (Kabatek 2008: 7). 
constantes por parte de los gramáticos de la época. Entretanto, en 1770, Carlos III maniobró con una Real Cédula que obligaba al uso exclusivo del castellano en aquellas tierras que abarcaban su reinado. Con ello, desde la religión y por la religión quiso acabar con un conflicto lingüístico que podría alterar la política territorial de su reino (cf. García Martín 2011). Y llegó el siglo XIX, época de independencias: de lo francés, en España; de lo español, en América. El castellano de la metrópoli, atrapado en un principio por el entorno de la invasión napoleónica ofrecía también resistencia a los elementos galos, en tanto que América comenzaba a defender su idiosincrasia lingüística para marcar sus diferencias con España, aunque, paradójicamente, acabó recurriendo a una norma peninsular con objeto de que América entera se mantuviera unida políticamente en su lucha contra la metrópoli (cf. Sánchez Méndez 2011).

Sirva este panorama general para poner en antecedentes la interacción entre lo social y la lengua. En medio de estos aires, se abrirá espacio una tradición discursiva epistolar que requerirá de unas alertas metodológicas para su estudio, las cuales pondremos de manifiesto en el siguiente epígrafe.

\section{Algunos problemas metodológicos en el acceso al estudio de la tradición discursiva epistolar en España y América (ss. XVIII y XIX)}

\subsection{Problemas en la evaluación de las actitudes implícitas}

Muchas de las conclusiones que extraeremos de las actitudes implícitas en la tradición discursiva epistolar salen a la luz por el reflejo en la escritura de un no querer ser, pero que se manifiesta inconscientemente. El investigador debe tamizar la transparencia para eludir un corolario engañoso. En el caso del examen de las cartas privadas, ha de apelarse a un conocimiento más exhaustivo sobre cómo se desarrolló esta tradición discursiva. Así, entre las preguntas que conducen a formalizar las respuestas de acceso caben varias: 1) cuál es la importancia de las fuentes consultadas en la evaluación coherente de los textos;2) cuál fue el inicio de la tradición discursiva epistolar y cuál su desarrollo formal; 3) quién escribía las cartas y qué impacto puede tener este hecho sobre los resultados de la investigación, y 4) teniendo en cuenta las cuestiones anteriores, qué repercusiones tiene este género en la delimitación de los rasgos diatópicos, diastráticos y diafásicos desde el concepto de actitudes linguiísticas implícitas. Justifiquemos brevemente cada pregunta.

\subsubsection{El análisis de las fuentes epistolares}

Desde que Enrique Otte (1966, 1968 y 1969) $)^{2}$ reavivara el estudio de estos documentos en los años sesenta de la pasada centuria, muchos trabajos se han realizado con el apoyo de sus aportaciones. Sin embargo, el rescate de estos textos no se hizo desde la mirada de un filólogo, sino desde la de un historiador. Y si bien nadie duda de la importancia del reflejo social de unos escritos que actuaban de espejo de costumbres, también es cierto que el retoque formal de la versión fuente elimina la posibilidad de acercarse con exactitud al meollo de la interpretación filológica. Parece evidente que en el examen de las actitudes explícitas la adaptación gráfica no altera el valor del producto, pero si se quiere indagar en la evolución e impacto de los cambios

\footnotetext{
${ }^{2}$ Francisco Ruiz Fernández (1993) llevó a cabo una tesis doctoral, en la que se transcribieron estrictamente muchos de los documentos de Enrique Otte.
} 
de norma inducidos por una actuación inconsciente de los protagonistas, la labor se complica, pues acabará seguramente en respuestas incoherentes. Pongamos un botón de muestra.

En el primer tercio del siglo XIX, un poeta costumbrista peruano, Felipe Pardo y Aliaga $(1945,56)$, describe de la siguiente manera al general Gamarra:

Era como hombre en privado un perfecto caballero. Afable en su trato, generoso, instruído y elocuente, al extremo de haber, con una sola palabra en quechua, hecho arrodillar de un golpe a 12.000 indios en el Cuzco, a quienes arengaba. Sabía bien el latín, el francés y hablaba castellano como un madrileño.

Este reflejo de actitud externa hacia la forma de hablar del general no podría corroborarse desde el punto de vista filológico con el simple análisis de sus cartas, si estas son consultadas desde fuentes que no respetan la grafía original. De hecho, en la recopilación de sus misivas, publicadas en 1952, se transcribe de manera estricta la letra del general — con la salvedad del sistema puntuario y los acentos-, pero aquí hay una mezcla curiosa de documentación que podría llevar a pensar, quizá, que, efectivamente, Gamarra hablaba como un castellano, pues se incluyen cartas transcritas del puño y letra, y otras que se extraen de publicaciones en la prensa de la época. Naturalmente, la primera lección que nos da el concepto de tradiciones discursivas es que partimos de fuentes radicalmente distintas, a pesar de que están inscritas en un mismo género. La prensa solía adaptar las grafías manuscritas con objeto de homogeneizar la escritura y eliminar tipos (cf. Rivas Zancarrón 2010). Este apunte nos pone en guardia sobre el hecho equívoco de intentar emitir conclusiones desde textos manipulados por otra tradición. Efectivamente, las cartas extraídas de la prensa regularizan la distinción gráfica entre /s/ y $/ \theta /$, a pesar de que la pronunciación de la gente común de la época se ha demostrado claramente seseante, con lo que, si el autor de la recopilación anuncia que ha transcrito fielmente, el filólogo puede llegar a pensar que la apreciación de Pardo y Aliaga respondía a la realidad. Esta inducción se vería inmediatamente desmontada, si se le echa un ojo a otras cartas transcritas de la mano de Gamarra, pues aquí no solo es claro el seseo ( $A$ Acabo de resivir el oficio de V. E. en que me previene no comprometa...»; [...] «fuersas», [...] «es preciso conduirlos serrandolos en las Yglesias» [Gamarra 1952, 4]), sino que se escapan numerosas ultracorreciones («divición», por ejemplo [op. cit., 4]), que dejan en evidencia la condición seseante del general. Muy posiblemente engañara a Pardo y Aliaga la articulación ápicoalveolar de Gamarra - coincidente con la de un castellano de Madrid y genuina de determinadas zonas americanas, entre las que se encuentran algunos lugares de Perú-, y distinta de la predorsal generalizada. Ignoraba el escritor peruano que la idiosincrasia castellana exigía, además, la distinción entre alveolar e predorsodental sorda, que en absoluto se cumplía en el general.

Se podría ilustrar este epígrafe con múltiples ejemplos, pero baste solo uno para justificar la necesidad de acercarse correctamente a las fuentes y, así, llegar a interpretaciones acertadas.

\subsubsection{Condicionantes en el desarrolllo de la tradición discursica epistolar}

Las actitudes implícitas transparentadas en estas cartas tienen encaje en múltiples mundos: la ideología sobre la lengua en un periodo concreto, el grado de alfabetización, los antecedentes y normalización del sistema gráfico, la situación política, el prestigio social, los factores económicos, y un largo etcétera. Sin embargo, existe un detonante social que generó la 
escritura de cartas: la emigración a América. En los siglos XVI y XVII, también consta que los indígenas se sirvieron de este género para plantear y asentar reivindicaciones jurídicas, pero serán las cartas de emigrantes las que inicien el proceso de consolidación de este tipo discursivo. Las carencias de los más necesitados y las ilusiones que se proyectaban sobre el nuevo continente abrió un flujo migratorio a América que permitió a andaluces, extremeños y canarios, en los primeros siglos (XVI y XVII), y a catalanes, vascos, gallegos y asturianos - a partir sobre todo del XVIII - a probar suerte o a iniciar intercambios comerciales al otro lado del Atlántico. Los primeros reyes se mostraron reacios a estos trasiegos migratorios, pero los Borbones abrieron la veda a los traslados con las Leyes de Indias: el comercio se centralizaría en Cádiz y, con excepción en un principio de las Islas Canarias, que gozaba de privilegios de navegación directa, el resto de la población debía dirigirse a aquella ciudad para el embarque. Naturalmente, para una incursión filológica en las cartas es primordial tener conocimiento de estos flujos, pues nos ofrecen datos interesantes sobre emisor y destinatario, sin los cuales no podríamos determinar los reflejos diatópicos, diastráticos y diafásicos que se proyectan desde estos documentos. No basta, pues, con examinar corpora textuales y emitir conclusiones panorámicas sobre actitudes implícitas o explícitas, sino que es preciso hacer un filtrado por agentes de emisión y recepción, con objeto de evaluar por dónde se orientaba el cambio lingüístico. De esta manera, si quisiéramos analizar las implicaciones filológicas de epistolarios catalano-cubanos, por ejemplo, sería preciso conocer de antemano cuándo y por qué se produjeron los movimientos migratorios de estos sujetos sociales. Se sabe, así, que los catalanes frecuentaron sobre todo los países caribeños entre 1814 y 1832, quienes, a cambio de azúcar y tabaco, intercambiaban productos industriales. Según se sabe - y esto interesa al análisis sociolingüístico - viajaban varones de entre 10 y 25 años y ocupaban puestos de tendero, hasta el punto de que se extendió el término catalán para la designación del tabernero. De este modo, las cartas dejarán la impronta de la incursión de este tipo de hablantes con unas características sociales, sexuales y culturales concretas, que, filológicamente, tiene la peculiaridad — como ha señalado Cala Carvajal $(2003,28)$ - de testimoniar «el contacto de lenguas en la Cataluña decimonónica» y de dar cuenta de la asimilación al habla y a la sociedad cubanas. En una de estas cartas, un emisor cubano - que se sirve habitualmente de la expresión tabaco - adopta la voz sigarro para hacerla más comprensible a su interlocutor catalán: «Circunstancias inprevistas me han privado de bolberles a visitar, y de fumar en reunión algunos sigarros como dicen Vdes. por /h/allá» (apud Cala Carvaja 2003, 29). La oralidad de la que se impregna este tipo de textos se aleja de aquellas cartas más formulísticas y se acerca más a una escritura espontánea.

A partir del siglo XVIII y, especialmente, del XIX, estas misivas enquistaron sus formas hasta el punto de transformar una escritura de urgencia en un escribir artístico. Comenzaron a prodigarse manuales de estilo, en donde la composición epistolar no solo engrandecía la belleza de la lengua, sino que se instauraba como pretexto de buenas costumbres y educación. Este hecho sociológico marcó la doble trayectoria de tales composiciones, en donde el rasgo distintivo era precisamente el distinguirse en la sociedad: cuanto mejor se escribían las cartas, mayor sentimiento de buena educación y nivel social se depositaba en el receptor. No obstante, aunque la carga de prestigio moduló sin duda este género en toda su dimensión, la necesidad hacia otro en la distancia no tenía reparos en sacudirse los remilgos de la fórmula. Por esta razón, la distinción del estatus social del emisor y del receptor son básicas a la hora de determinar cuánto de diatopía o de diastratía salpicaba un texto concreto. 


\subsubsection{Identificación de emisor y receptor en las cartas}

Otro de los escollos metodológicos que habremos de salvar a la hora de conocer las actitudes lingüísticas implícitas en estos textos - a los que la tradición histórica ha denominado egodocuments ${ }^{3}$ - es el problema de la autoría material. En estos escritos, se da por hecha la presencia de un agente general, corporeizado en la figura de un inmigrante, un militar, un diplomático, un virrey o una dama de alta educación, pero no se discute si el individuo particular de cada uno de esos grupos fue el que llevó al papel su mensaje. Muy posiblemente, para la disciplina histórica estos matices carecen de importancia, pero son vitales para el análisis filológico, pues puede que estemos identificando rasgos no del agente que etiqueta un grupo, sino de un escribiente o pendolista. Sobre esta cuestión, los índices de analfabetismo evidencian las escasas probabilidades de que coincidiera el remitente con el que escribía, y, aun en el caso de que estos niveles se redujeran con el tiempo, los propios textos revelan que tal coincidencia no era muy plausible entre las clases acomodadas, que elaboraraban sus cartas al dictado. Sí es cierto que podría trazarse una línea, construida sobre la base de una ecuación de proporcionalidad inversa entre el nivel de instrucción y la pertenencia a una clase social, en donde el grado de alfabetización incidiría más sobre las clases pobres que sobre las acomodadas: las primeras, conforme aprenden a leer y escribir, empiezan a ser responsables de sus propias cartas, en tanto que las segundas, a pesar de estar alfabetizadas desde la infancia, se sirven de otras manos para su composición.

Es evidente que las estadísticas de analfabetismo no resuelven por sí solas la pregunta de si había coincidencia o no entre el emisor y el escribiente, pero estos textos ofrecen pistas constantes como para determinar con claridad quién fue el autor. Como señala Sierra Blas (2004), la mayor parte de usuarios de estos textos, los emigrantes, estaban poco familiarizados con la escritura, pues hasta el momento de partir no se habían visto con la necesidad de escribir. En muchas de las cartas, incluso aquellas compuestas casi al final de la centuria decimonónica, se revela la poca destreza de los emigrantes en el leer y escribir, aunque sí es verdad que, siguiendo la regla antes mencionada, eran autores de sus propios escritos, al estar mínimamente alfabetizados. Léase, si no, el siguiente fragmento de una carta compuesta en 1885 (apud Cala Carvajal 2003, 27):

Querido hermano, tomo la pluma para manifestarte que me a serbido de mucho pesar el recibir la tuya, y al ver que Vdes. se qreían que yo no sabía escribir. Mucho no sé, pero... si yo no he escrito, a sido porque cada bez que Vdes. escirben (sic) y Perico les escribe, yo leo las cartas de parte y parte y por eso nunca a sido mucho el apuro.

Como muestra de las decenas de ejemplos que podrían justificar las palabras escritas en este epígrafe, ofreceremos dos fragmentos. El primero reproduce el mensaje de una dama de alta educación del siglo XIX (de 1847, concretamente), Rosario Puga, tía del prócer chileno Demetrio O'Higgins, en donde da a entender que, aunque sabe leer y escribir, se sirve de pendolistas (en este caso, una tía suya a la que pilla falseando su dictado):

\footnotetext{
${ }^{3}$ El término se le debe, según Álvarez Gila y Angulo Morales (2016) a Jacob Presser, quien colocó esta etiqueta a unas fuentes documentales del estilo de autobiografías, libros de viaje, memorias, etcétera. Luego fue matizado por Rudolf Dekker (2002).
} 
Como tú sabes, es de lo más hábil para todo. Como yo ya no sabía leer, la tenía para que también me leyera las cartas: ella era todo para mí, pero le he hecho una pillada: no me las leía enteras ni ponía lo que le dictaba ${ }^{4}$ (Vergara Quiroz 1987, 165).

La segunda muestra elegida es una carta del general Gamarra $(1952,89)$ al vicepresidente Antonio de la Fuente, en la que anuncia explícitamente que no fue el autor material del escrito:

Tuve el gusto de recibir la estimable de V. del 17, que trajo Arrisueño, y con ellas las copias de los tratados de paz. Los contínuos dolores de cabeza que me atormentan, no me permiten escribir a V. de mi puño, ni ser tan minucioso como quisiera en estas circunstancias. ¿dolor o querer hacerlo bien?

El reflejo explícito de la autoría dentro del texto facilita, naturalmente, la labor del filólogo en el escrutinio de los rasgos orales y en la representación de los indicios del cambio lingüístico.

\subsubsection{Incidencias metodológicas en la descripción de los rasgos diatópicos, diastráticos y diafásicos}

Para el detenimiento en los rasgos dialectales, sociales y de estilo de lengua, intuibles desde actitudes implícitas, es necesario, en primer lugar, considerar cada uno de los problemas planteados en los apartados anteriores, pues habrá que indagar sobre las causas sociales que condujeron a la creación de esta tradición discursiva y, además, identificar al autor material de la carta — descartando aquí que fuera distinto al firmante —. Luego, se mostrará pertinente un análisis exhaustivo del tipo de fuentes (si originales, si transcritas de manera estrecha o laxa). Solo así, la descripción de estos rasgos podrá ofrecer resultados fiables.

Los reflejos diatópicos determinarán actitudes implícitas manifestadas, fundamentalmente, en la grafía, que será filtrada desde los parámetros antes expuestos. Esto permitirá establecer la existencia de una regularidad ortográfica desde patrones distinguidores (una parte de España) o seseantes. El amplio corpus del que disponemos para el análisis ${ }^{5}$ muestra la existencia de seseo diatópico en Andalucía, Canarias y América, reflejado tanto por la presencia de la grafía $s$ para la pronunciación predorsodental sorda, como la de $c$ o $z$ para la representación de la alveolar sorda (ultracorrecciones), que delatan el desconocimiento de la distinción por un deseo de acercarse a la norma distinguidora peninsular. Los múltiples ejemplos de las misivas escritas en la península en territorio castellano advierten de una

\footnotetext{
${ }^{4}$ Es evidente que el «no sabía leer» de este texto es un «no podía leer». Sería interesante, a este respecto, investigar la proliferación de este fenómeno en la tradición discursiva epistolar, que llega hasta el siglo XIX, y del que quedan restos en algunas lenguas románicas (en castellano se documenta en La Celestina). En algunas cartas de Simón Bolívar, como el fragmento que reproducimos más abajo dirigido a Manuela Sáenz, nos topamos también con este valor inusitado, pero diacrónicamente viable: «Estoy tan cansado del viaje y de todas las quejas de tu tierra que no tengo tiempo de escribirte con letras chiquititas y cartas grandotas como tú quieres. Pero en recompensa si no rezo, estoy todo el día y la noche entera haciendo meditaciones eternas sobre tus gracias y sobre lo que te amo, sobre mi vuelta y lo que harás y lo que haré cuando nos veamos otra vez. No puedo más con la mano. No sé escribir» (Gobierno Bolivariano de Venezuela 2017, 161).

${ }^{5}$ Entre algunas de las obras consultadas y puestas a disposición del investigador podríamos citar las siguientes: Agustín Gamarra (1952); González de Chávez (1982); Martínez Martín (1989); Mayans y Siscar (1989); Melin y Rivero (2008); Eyzaguirre (1945); García-Huidobro Becerra (2015); Manuela Sáenz (1986); Silva Castro (1954); Vergara Quiroz (1987); Gobierno Bolivariano de Venezuela (2017); Portal de Archivos Españoles (PARES) [2017]; Enrique Otte (1966, 1968, 1969), y un largo etcétera.
} 
regularidad pasmosa en el puño y letra entre la predorsodental sorda (representada por $z, \mathrm{y}$ escasamente por $c$ ) y la alveolar sorda (cristalizada en $s$ ). Este hecho muestra que las reformas académicas no tuvieron apenas impacto en el individuo particular, aunque sí en la prensa, que buscaba otros modelos gráficos.

Las diferentes actitudes que revela la distinción sexual a la hora de plasmar por escrito los contenidos es otro aspecto que habrá de tenerse en cuenta. Según se explicita por la forma de composición de estos textos, serán las mujeres las más cuidadosas en el trato de la grafía y el estilo. Naturalmente, hablamos de las féminas de más alta instrucción o de clases acomodadas, las cuales, al atribuírseles el papel de educadoras en el hogar familiar, acababan siendo más exigentes y conservadoras. No hay espacio para reseñar la gran cantidad de fragmentos en los que de manera explícita este sexo apostaba por una lengua más controlada y homogénea.

Por último, el estilo de lengua es otro de los condicionantes que han de tratarse en la descripción de la tradición discursiva epistolar. La composición de las cartas no escapaba tampoco a las variaciones producidas desde los cambios de registro y, aunque los escritos que se hacían enfrentando a iguales eran más susceptibles de impregnaciones dialectales, cuando estos se dirigían a un receptor desconocido, el sistema implícito de actitudes se trastrocaba. De hecho, la aparición de manuales de estilo para la formalización de las misivas no hacía más que confirmar la presencia de fórmulas específicas para cada tipo de destinatario. Así, en la traducción que hizo Benito Avalle $(1762,214)$ de la obra de François de Callières $(1717)$, y en el capítulo XVII, que habla de «Lo que se debe observar escriviendo cartas, y los preceptos para aprender à escrivirlas», se lee lo siguiente:

Quanto à las personas, se debe tener la misma consideracion, como havemos dicho, assi escriviendo, como hablando; porque, ò es persona superior, que escrive à otra inferior, ò de inferior à superior, ò de igual à igual. Ademàs de esso es necessario atender, si es una muger, ò un hombre Militar, un Magistrado, una persona pùblica, ò un Eclesiastico, de cuyas distinciones depende la Cortesanìa.

\subsection{Problemas metodológicos en la evaluación de las actitudes explicitas}

Las actitudes ante la lengua que se hacen explícitas en las cartas son las menos susceptibles de ser filtradas ni desde el punto de vista del método, ni desde el origen de las fuentes elegidas para la investigación, ya que aquí no se evalúa la forma, sino el contenido. Eso sí, son quizá las más interesantes para desentrañar el universo en el que se fundamentan los corolarios de las actitudes implícitas, siempre que un historiador no nos haya advertido antes de estos detalles. Así, nos avisan de quién actuaba de agente material de estos textos, esto es, si el remitente los escribía de puño y letra, o si pasaban por la mano de un pendolista (cf. 3.1.3). Y, desde luego, nos dejan claro cuál es la aspiración normativa ante la lengua del emisor, como en la siguiente carta del libertador Simón Bolívar (2017, doc. 302), fechada en 1828:

Mi querido Fernando: Contesto a tus dos apreciables cartas de Caracas donde sé que has llegado y en lo cual has hecho muy bien, no pudiendo ya mantenerte en los Estados Unidos. Sin embargo, debo decirte que a mi salida de Caracas, dejé dispuestos los medios para tu subsistencia allí. Haces muy bien en entretenerte con tus libros y yo prefiero que sean españoles para que te perfecciones en el idioma: te encargo que te ejercites en copiar el castellano a fin de que curses la letra y te perfecciones en la ortografía, pues mi deseo es 
que vengas a mi lado a servirme en mi correspondencia. En otra ocasión te diré a dónde te has de incorporar conmigo.

Como es de esperar, la mayor parte de actitudes explícitas se dejan leer en las cartas de próceres, gramáticos e intelectuales (especialmente mujeres de educación esmerada). La gente de a pie, más preocupada por saber de sus familiares, apenas emiten valoraciones sobre la lengua, salvo aquellas que advierten sobre sus carencias en el leer y escribir.

\section{Conclusiones}

El efecto que pudo provocar en el cambio lingüístico las actitudes de los hablantes en dos siglos como el XVIII y el XIX solo podrá verse testimoniado feacientemente — con el rigor que requiere el análisis filológico-, si se acometen las labores necesarias de filtrado metodológico sobre el corpus textual. Para esta tarea, se precisa poner en funcionamiento un motor explicativo general que arranque desde el concepto de «tradiciones discursivas». Esta teoría permitirá catalogar este tipo de representaciones escriturales como un género textual con vida propia, que somete sus contenidos a las estrecheces de un corsé formulístico especial y que permite marcar las diferencias con otras manifestaciones cristalizadas en letras. Desde esta perspectiva, las cartas serán analizadas como textos, en los que individuos particulares plasmarán lingüísticamente sobre el papel sus incapacidades o habilidades, sus vergüenzas dialectales - ya sea de manera consciente o inconsciente-, los dejes de una buena educación o las huellas de un mal aprendizaje, las aptitudes para mudar el registro en función del destinatario, los deseos de ser puristas según el sexo, o la evolución de la lengua en la que escriben de acuerdo a una época. Y todo esto desde la mirada atenta de unas fuentes que distorsionarían la realidad de los resultados al ser vertidas en letra de molde. Con la precaución que exige el método para enfocar el objeto de estudio con nitidez, quizá pudiera la historia de la lengua refinar algunas de sus conclusiones sobre el desarrollo de fenómenos internos desde la ayuda de formulaciones teóricas nacidas en la sociolingüística diacrónica.

\section{Bibliografía}

Agheyisi, Rebecca y Fishman, Joshua. 1970. «Language attitude studies: A brief survey of methodological approaches». Anthropological Linguistics 12: 137-157.

Álvarez Gila, Óscar y Angulo Morales, Alberto, eds. 2016. From the Records of my Deepest Memory. Personal Sources and the Study of European Migration, 18th-20th centuries. Bilbao: Universidad del País Vasco.

Appel, Rene y Muysken, Pieter. 1987. Language contact and bilingualism. London: Arnold.

Avalle, Benito. 1762 [1744]. La urbanidad y cortesia universal que se practica entre personas de distincion. Traducida del idioma frances al castellano por... Madrid: Imprenta de Miguel Escrivano.

Blanco de Margo, Mercedes. 1991. «Actitudes hacia la lengua en la Argentina. Visión diacrónica». Revista de Lingüística Teórcia y Aplicada 29: 197-214.

Blas Arroyo, José Luis. 1999. «Las actitudes hacia la variación intradialectal en la sociolingüística hispánica». Estudios Filológicos 34: 47-72. 
Cala Carvajal, Rafael. 2003. «La voz de los catalanes emigrados a Cuba (s. XIX). Testimonios epistolares». Boletín Americanista 53: 190-33.

Callièrs, François de. 1717. De la science du monde et des connaissances utiles à la conduite de la vie. Paris: E. Ganeau.

Carranza, Miguel A. 1982. «Attitudinal research on Hispanic language varieties». In Attitudes towards language variation, edited by Ellen Ryan y Howard H. Giles, 63-83. London: Edward Arnold Publishers Ltd.

Coseriu, Eugenio. 1977. El hombre y su lenguaje. Madrid: Gredos.

Dekker, Rudolf. 2002. «Jacques Presser's heritage: egodocuments in the study of history». Memoria y Civilización 5: 13-39.

Eyzaguirre, Jaime. 1945. «Correspondencia de don Demetrio O’Higgins». Boletín de la Academia chilena de la Historia 33: 39-55.

Fasold, Ralph W. 1984. The sociolinguistics of society. Oxford: Basil Blackwell Ltd.

Gamarra, Agustín. 1952. Epistolario. Lima: Facultad de Letras de la Universidad Nacional Mayor de San Marcos.

García-Huidobro Becerra, Cristóbal. 2015. Epistolario de Manuel Montt (1824-1880). Santiago de Chile: Centro de Investigaciones Diego Barro Arana.

García Martín, José María. 2011. «Revisión de algunas ideas sobre política e ideología lingüísticas en el siglo XVIII español». Cuadernos de la Ilustración y el Romanticismo 17: 1-39.

Gobierno Bolivariano de Venezuela. 2017. Archivo del libertador. Gobierno de Venezuela: http://www.archivodellibertador.gob.ve.

González de Chávez, Jesús. 1982. «Notas para la historia de la emigración canaria a América. Cartas de emigrantes canarios. Siglo XVIII». In V Coloquio de Historia CanarioAmericana, 111-140. Gran Canaria: Cabildo Insular de Gran Canaria.

Kabatek, Johannes. 2000. «L'oral et l'écrit — quelques aspects théoriques d'un 'nouveau' paradigme dans le canon de la linguistique romane». Kanonbildung in der Romanistik und in den Nachbardisziplinen, 305-320. Tübingen: Narr.

Kabatek, Johannes. 2008. «Introducción». Sintaxis histórica del español y cambio lingüístico. Nuevas perspectivas desde las Tradiciones Discursivas, 7-16. Frankfurt am Main: Iberoamericana Vervuert.

Koch, Peter y Oesterreicher, Wulf. 2011. Gesprochene Sprache in der Romania. Französisch, Italienisch, Spanisch. Göttingen: De Gruyter.

López Morales, Humberto. 1989. Sociolingüística. Madrid: Gredos.

Martínez Martín, Laura. 2010. «The Correspondence of Asturian emigrants at the end of the beginning of the 20th centuries: the case of José Moldes». Language and the Scientific Imagination: Proceedings of the 11th Conference of the Internacional Society for the Study of European Ideas (ISSEI), 1-18. Helsinki: Helsinki University.

Mayans y Siscar, Gregorio. 1989. Epistolario. Valencia: Artes Gráficas Soler.

Melin, Chantal y Rivero, Franyutti. 2008. Documentos lingüísticos de la Nueva España. Golfo de México. México: UNAM.

Ministerio de Educación, Cultura y Deporte. 2017. Portal de Archivos Españoles (PARES). Madrid: http://www.w3c.es. 
Otte, Enrique. 1966. «Cartas privadas de Puebla del siglo XVI». Jahrbuch für Geschichte von Staat, Wirtschaft und Gesellschaft Lateinamerikas 3: 10-87.

Otte, Enrique. 1968. «Mercaderes Burgaleses en los inicios del comercio con México». Historia Mexicana XVIII 1: 108-144.

Otte, Enrique. 1969. «Die europäischen Siedler und die Probleme der Neuen Welt». Jahrbuch für Geschichte Lateinamerikas 6: 1-40.

Pardo y Aliaga, Felipe. 1945. «Semblanzas peruanas». Boletín de la Academia chilena de la Historia 33: 63-67.

Rivas Zancarrón, Manuel. 2010. «Impacto de las reformas ortográficas en la tradición escrita en los siglos XVIII y XIX». Gramática, canon e historia literarias, editado por Fernando Durán López y Victoriano Gaviño Rodríguez, 327-348. Madrid: Visor.

Rivas Zancarrón, Manuel. 2017). «La autoridad del Fuero Juzgo en el Diccionario de Autoridades». Palabras. Vocabulario. Léxico, editado por Florencio del Barrio de la Rosa, 299-321. Venezia: Edizioni Ca'Foscari.

Rojas, Darío. 2015. «Ideologías y actitudes lingüísticas en el Chile hispanohablante de la segunda mitad del siglo XIX». Tesis doctoral, Universidad de Valladolid.

Rona, José Pedro. 1974. «La concepción estructural de la sociolinguística». Antología de estudios de etnolingüística y sociolingüística, 203-216. Méjico: UNAM.

Ruiz Fernández, Francisco. 1993. «Fonética del español de América del siglo XVI en cartas de emigrados andaluces a Indias». Tesis doctoral, Universidad de Sevilla.

Sánchez Méndez, Juan Pedro. 2011. «Ideología y modelos lingüísticos: Andrés Bello y la ilustración hispanoamericana». Cuadernos de la Ilustración y el Romanticismo 17: 127.

Sáenz, Manuela. 1986. Epistolario. Quito: Banco Central del Ecuador.

Schlieben-Lange, Brigitte. 1983. Traditionen des Sprechens. Elemente einer pragmatischen Sprachgeschichtsbeschreibung. Stuttgart und Berlin: Kohlhammer.

Sierra Blas, Verónica. 2004. «Puentes de papel. Apuntes sobre las escrituras de la emigración». Horizontes Antropológicos 22: 121-147.

Silva Castro, Raúl. 1954. Cartas chilenas (siglos XVIII y XIX). Santiago de Chile: Academia chilena de la Historia.

Vergara Quiroz, Sergio. 1987. Cartas de mujeres en Chile. 1630-1885. Santiago de Chile: Editorial Andrés Bello. 